\title{
The Effect of Science and Technology Ethics on Science and Technology Innovation
}

\author{
Wei Yang \\ School of Marxism \\ Wuhan University of Science and Technology \\ Wuhan, China
}

\begin{abstract}
The promoting effect of science and technology development on society is evident in the contemporary era. However, the side effects or potential negative impacts of science and technology in social development such as the threat of nuclear weapons, environmental pollution, ecological unbalance, resources shortage, population crisis, etc. have spread to the whole world, and attract more and more attention. Especially when scientific researches go deep into life sphere of human beings, such as human genome and genetic research, artificial reproductive technology and cloning technology, having made great achievements one after another and being tried to put into practice, and give rise to a series of corresponding social, legal and ethical problems, people always raise the question with some worries: Should we give proper guidance and restriction to the development of science and technology, while sighing that "science and technology are double-edged sword"?
\end{abstract}

Keywords-science and technology ethics; crisis; science and technology innovation

\section{INTRODUCTION}

Since human beings come into being, the first problem they faced with is survival. The means of production for which mankind depends mainly derive from nature. Therefore, human beings have had close contact with nature since their birth. The people's understanding of nature mainly relies on the development of science and technology. The rapid development of science and technology helps mankind gradually get rid of ignorance, gives mankind the ability to recognize and transform nature, and promote social and economic growth. However, while promoting economic growth, the nature that mankind live by is suffering serious damage: Excessive use of resources, the environment is polluted, and ecology is destroyed. In the meantime, mankind is suffering from the wild retaliation of nature: dust storms, mudslides, fog and haze and so on. A series of environmental problems such as deteriorating relationship between man and nature began to plague humankind.

\section{SOCIAL CRISIS TRIGGERED BY SCIENTIFIC AND TECHNOLOGICAL INNOVATION ACTIVITIES}

Since the 21 st century, science and technology have evolved in depth from the microscopic to the macroscopic levels with more breakthroughs in subjects and the trends of cross-integration are more and more obvious. The original breakthroughs in some major scientific issues such as materials structure, the evolution of the universe, the origin of life, and the nature of consciousness are opening up new frontiers and new directions; fields such as information networks, artificial intelligence, biotechnology, clean energy, new materials and advanced manufacturing are making a great leap; disruptive technologies are constantly emerging, giving birth to new economy, new industries, new formats and new models, which will exert an unprecedented and profound impact on mankind's modes of production, lifestyles and even thinking modes. Scientific and technological innovation plays an increasingly important role in coping with the common challenges of mankind and achieving sustainable development.

At the same time, people compare science and technology to double-edged sword and "Pandora's Box," and this is very vivid. Indeed, there are many good things in this "magic box" of science and technology, but in some cases, they are used improperly, which may not produce good results but negative effects. In the history of science and technology, there are so many examples of such things as gunpowder, atomic energy, chemistry, biotechnology and so on, while creating wealth and material civilization for mankind, they also bring about deterioration in the tools of war, environmental pollution and living conditions. Actually, there is no good or evil in science and technology themselves. However, the people involved in science and technology activities have different considerations and pursuits of interests, which lead to two different results of science and technology.

"People should grasp inherent law of things through indepth exploration, be self-disciplined and apply the theory to practice." To develop science and technology, it is necessary to use them. In human society, the conditions for making a thing work are nothing more than people, money and things. Among the three conditions, people are the main body and the most active factor. In scientific and technological innovation, it is more prominent that human is the first factor. A scientific achievement or a kind of technological means can often be used to bring benefits to mankind and meet someone's evil needs simultaneously. For example, the application of nuclear energy has both positive and negative aspects of the application of nuclear 
power plants and application of nuclear weapons. Nuclear energy is an environmentally-friendly and high-efficiency source. However, once is used on the battlefield, that is, nuclear weapons, nuclear energy will be a devastating blow to mankind. Therefore, not all developments and applications of modern science and technology act according to the good wishes of people. They have brought a certain degree of negative impact on human survival and social life in the course of their development. There are several main cases:

- Due to the restriction of conditions, the value of scientific discoveries and inventions is usually evaluated by experts from the perspective of pure science and technology in the development of science and technology. When people use technological means to transform the objective world, they only expect good results without considering the negative effects they may have. When the dangers are fully exposed to the public, it often spends a lot to govern and sometimes it is even completely irreparable. For example, the phenomena of acid rain, greenhouse effect, the ozone hole and so on caused by modern industrialization are not realized by people when they started the activities of science and technology innovation.

- For the sake of narrow political and economic interests of their own countries and nations, some people use powerful science and technology to damage the interests of other countries and nations. For example, during World War II, biotech workers in 731 troops in Japan served as "weapons" to destroy humankind. Today, some countries rely on their own strong economic power and military science and technology interfering in the internal affairs of other countries, even triggering wars on the territory of others and using science and technology as a "tool" for their domination of the world.

- For the sake of small groups, some people damage the public, national even human interests. For example, driven by profit, some local enterprises discharge pollutants to nature, rivers and lakes, and atmospheric air while producing goods by using scientific and technological means, which caused that the living environment that mankind depends on become worse because of pollution. For example, some enterprises with few environmental measures, for example, local small-scale paper mills, directly discharging pollutants into the rivers, lakes and seas have caused serious pollution to water resources. The consequences of such pollution are far-reaching.

- For the sake of personal desires, some people damage the interests of others, collective and national interests using science and technology. Such as computer hacking created computer viruses and caused data loss and system crash in order to steal other people's information or money. It seriously affected the normal order of human society and social life. For example, the famous virus "Panda burning incense" affected the whole country in March 2007.

- Intractable ethical problems have been caused for human beings blindly abuse and misuse scientific and technological achievements such as reproductive techniques, euthanasia and so on. In particular, the abuse of cloning technology will lead to bioethical confusion and undermine the normal order of human life.

\section{The NeCESSITY OF SCIENCE AND TEChNOLOGY ETHICS INVOLVING IN SCIENTIFIC AND TECHNOLOGICAL INNOVATION}

Scientific ethics refers to the principle for human society and nature that people engage in the innovation of science and technology. They are the values, social responsibilities and codes of conduct that the subject of scientific and technological innovations should hold. It includes bioethics, information ethics, ecological ethics, new material ethics and military ethics and so on. The ethics of science and technology is the moral guidance for scientific and technological innovation activities and the sum of the moral principles and rules that regulates the relations among science and technology workers, science and technology community and society. The importance of scientific ethics lies in the fact that on the one hand, the use of scientific and technological innovations can be guided by a clear moral rationality so as to minimize the possibility of using scientific and technological innovations for evil purposes; on the other hand, as moral reason, the ethics of science and technology makes up for the deficiency of purely scientific rationality and enhances the moral responsibility of scientific and technological innovators for the consequences of scientific and technological development so as to minimize the unconsciousness of scientific and technological rationality in the negative social role with the moral rationality.

In general, law and morality are two major measures for maintaining social order. The most prominent feature of legal regulation and control is the compulsion and high cost. As a kind of informal institutional arrangement, moral restraint is characterized by extensiveness and persistence. In view of industry features of science and technology, daily operation needs to be driven by moral self-discipline rather than laws of law even more. Therefore, the ethics of science and technology is the most effective discipline mechanism in science and technology. Under the current situation that the effectiveness of science and technology is getting stronger and stronger, it is very necessary to make ethical evaluation on scientific research, especially on some high-tech applications, or give some restrictions and guidance. To do so, on the one hand, can prevent abuse to some extent and the potential harm be turned into reality; on the other hand, scientific research can help us find out its own limitations or certain shortcomings so as to rectify and compensate for it in time and improve its theory and technology. It can be asserted that the necessary value assessment and guidance for scientific research and technology application will not 
hinder the progress of science and technology; on the contrary, it is more conducive to the sound and normal development of science and technology.

It has long been believed that science and technology are progressive in nature and beneficial to all mankind influenced by the theory of value neutrality of science. Science and technology have no value preference. Science explores the factual knowledge of the universe, and ethics explores the value of human society. Therefore, technology itself has nothing to do with ethics and technology is neutral. With the combination of modern science and technology, tremendous changes have taken place. Especially the development of modern high technology has posed a severe challenge to human ethics. The negative effects of science and technology have been revealed constantly, triggering a series of ethical problems. The relationship between ethics and technology has drawn much attention. In this regard, mankind should re-examine the relationship between technology and ethics, go beyond theories of value neutrality of science, making science and technology contribute to the well-being of mankind.

Although it is not inherent in science and technology itself, science and technology ethics is a kind of exterior control means of science and technology. Science and technology ethics can become an internal force in science and technology activities by means of internalizing in science and technology workers. The ethics of science and technology is a set of ethical rule system that can tell and educate people: "what kind of scientific and technological activities are good or evil; what kind of scientific and technological activities should or should not be done; people should contribute to mankind but do evil through science and technology activities. "When these rule systems are universally accepted and become accepted as a code of conduct to adjust people's relations in science and technology activities, the overwhelming majority of people will follow these codes of conduct to conduct scientific and technological activities voluntarily and resist bad scientific and technological behaviors consciously.

\section{SCIENCE AND TECHNOLOGY ETHICS IS THE CODE OF CONDUCT FOR SCIENTIFIC COMMUNITY CARRYING OUT}

\section{SCIENTIFIC AND TECHNOLOGICAL INNOVATION ACTIVITIES}

The social responsibility of the scientific community is related to the moral orientation and moral norms of the entire society. The whole society must pay attention to the issue of social responsibility of science and technology ethics and scientific community. In the face of all kinds of new technological achievements, people should not overlook potential and reality dangers, but use scientific and technological achievements correctly to bring benefit for mankind and safeguard human's life and health thereby avoiding the negative impact on society caused by improper use of scientific and technological achievements to the utmost extent. Scientific ethics is the civilization idea in science and technology innovation and modern society. It is an inexhaustible spiritual power of science and technology innovation, a common code of conduct for science and technology innovation, and an advanced cultural atmosphere for scientific and technological innovation.

All the dangers that science and technology brought to mankind should not be attributed to itself. However, the use of scientific and technological methods, scientific and technological activities, and scientific and technological achievements clearly permeates the factors of social culture and ethics. The "able" in science is not ethically "deserved." As an important part of advanced culture, the development direction of ethics of science and technology is of great significance to the establishment and improvement of social ethics and morality. Since the 20th century, science and technology have developed at an unprecedented speed and scale. With unprecedented socialization, some scientific achievements have been abused, which caused devastating disaster for mankind, other lives and ecological environment on earth. Paying more and more attention to ethical norms of scientific activities and strengthening the ethical and moral responsibilities of scientists have become hot issues that scientific community and the public are concerned about. The challenge of scientific ethics and morality not only comes from the development of science and technology, but also from people's utilitarian and unfairness that brought by the impact of the global market economy, information asymmetry and development imbalances.

Science and technology ethics is not the ethical and moral relationship between man and science, but among human beings with human society as an intermediary; for the reason that human beings advocate protecting the environment and even coordinate the relationship between man and nature ethically, the ultimate concern of them is to coordinate the relationship among people. The reason why people stress the behaviors that breaking the ecological balance and polluting the environment unethical and deserved to be condemned is due to that the acts undermine the overall and long-term interests of mankind. The deep problems lie in that viewed from the actual situation, the destruction and pollution caused by some people harm the interests of others directly and indirectly. Therefore, the relationship between these people and nature inevitably becomes an organic composition of the relationship among people and thus has ethical implications. In view of the overall and long-term fundamental interests of human existence and development, people should and must maintain the balance of ecosystems and protect the biodiversity of animal and plant resources so that the human ecological environment will not suffer from damage and pollution because of the exploitation of natural resources.

However, the utilitarianism of human beings also poses a serious challenge to scientific ethics. Lu Yongxiang, former vice chairman of NPC Standing Committee and president of the Chinese Academy of Sciences, once said: "due to unrealistic pursuit of quick results, young scientists may be impetuous and misconduct; famous scholars may be conservative or treat others' contribution unfairly by using their reputation improperly; scientists in bad conditions may wish to change their living and working conditions by improper behaviors; scientists in good conditions may treat others' contribution unfairly by using their advantages of 
position and resource properly; scientists, engineers may also be tempted by benefits and put personal interests on national and public interests." These are all problems to be solved urgently in the construction of scientific ethics.

Scientific ethics and morality stem from the inherent requirements of scientific and technological innovation. They are based on the common and fundamental human values. The exploration and truth of science and technology demand that mankind can make unremitting efforts to seek truth from practices. However, the duality of science and technology requires that mankind should abide by ethics and bring benefit to mankind. View of science requires people to seek truth from practices and bring benefit to human beings, and view of society requires people to respect human dignity and human rights and to respect the harmonious and sustainable development between man and nature, while view of nature requires people to respect life, conserve biodiversity, and protect ecosystem.

\section{The BASIC PRINCIPLE AND PATH OF SCIENCE AND TECHNOLOGY ETHICS IN SCIENTIFIC AND TECHNOLOGICAL INNOVATION ACTIVITIES}

Objectively speaking, science and technology ethics is an effective regulation of realistic science and technology activities, and it embodies the purpose of harmonious development of human society and personal selfimprovement, which requires that the construction of science and technology ethics must follow certain principles. First, we must abide by the principle of synchronous and unified development of science and technology as well as ethics. Scientific and technological innovation is the driving force of social development and progress. Scientific and technological innovation not only promotes the process of social material civilization, but also the development of social spiritual civilization. The social functions of scientific and technological innovation are becoming more and more prominent. In the process of scientific and technological innovation, scientific activities are combined with ethical ideas. Therefore, the construction of high-tech science and technology ethics must aim at the progress of ethics. Second, it must follow the principle of promoting social progress. The healthy development of science and technology innovation cannot be separated from social progress. The ethical issue of science and technology is not just a purely scientific or technical but a social one. If science and technology innovation cannot be used properly, its destructive power is enormous. Therefore, making it possible to maximize the development of scientific and technological innovation in line with social development has become a problem that science and technology ethics is faced with.

For the construction of scientific ethics and morality, on the one hand, it is necessary to strengthen the research on scientific ethics and morality and develop it on the basis of deepening scientific cognition. At the same time, we should pay attention to the dissemination and education of scientific ethics as well as the education and demonstration of scientific ethics. On the other hand, we must also improve democracy and supervision, be not blind faith of authority and encourage academic contention. At the same time, we must also improve the laws and regulations of national and international scientific ethics and the evaluation criteria and methods of science and technology innovation.

Science and technology has become one of the most important variables affecting the world economic cycle and the most important factor in determining the economic aggregate. Every scientific and technological revolution will expand economic aggregate and bring about a golden period of economic development. Science and technology is a double-edged sword. To make better use of it, human beings must pay attention to the role of scientific and technological ethics in it and make the spirit embodied in scientific and technological ethics going through the whole process of scientific and technological activities. Through scientific and ethical spirits, we should establish correct science and technology view, with which people and nature, people and society, and humans will live in harmony with each other. At the same time, we must gradually eliminate the evil but increase kindheartedness in humanity to continuously sublimate people's spirit by means of liberal studies, ethical religion, and social opinions, so that they can treat themselves, others and nature kindly. There are reasons to believe that in the face of the challenges posed by science and technology in the 21 st century, rational human beings will take a broad and long-term view to consciously establish a scientific and ethical outlook in the 21 st century that is compatible with the high-tech era of the 21 st century to serve and bring benefit to all human beings.

\section{CONCLUSION}

Science and technology as well as ethics promote the spiritual civilization of human society and play an important role in the continuity and development of human society. Science and technology are important ways of supporting human social activities. The progress and development of science and technology directly promote the progress and development of human civilization. However, due to the complexity and diversity of society, some science and technology activities have played a considerable negative impact on society while promoting the development of human beings. In order to give full play to the positive role of science and technology in the society, we must strengthen ethics as well as science and technology to guide and standardize scientific and technological innovation. Through the popularization, education, understanding of and deepening scientific and technological ethics knowledge in science and technology activities, science and technology activities develop in the direction of benefiting society.

\section{REFERENCES}

[1] Lu Yongxiang, Thoughts on Science and Technology Ethics [J]. Study Times, 2003, (1)

[2] Zhang Youliang, Science and Technology Ethics - the Only Way Getting Rid of Ecological Crisis [J]. Science (Academic Research), 2008,(27).

[3] Li Gang, Yang Hui, Liu Yan. A Brief Analysis of the Role of Ethics in the Development of Science and Technology [J]. Technology Innovation and Application, 2013 (21). 
[4] Ding Guizhi, Talking about Science and Technology as well as Ethics [J]. Economic Research Guide, 2015, (12).

[5] Jia Min, Zhang Hao, Talking about the Ethical Problems of Science and Technology Innovation [J]. Journal of Xingtai University, 2017, (2). 